\section{Check for updates}

Cite this: Mol. Syst. Des. Eng., 2020, 5, 14

\title{
MSDE emerging investigators 2020
}

\author{
Juan de Pablo and Neil Hammond (iD
}

\section{DOI: 10.1039/c9me90035g}

rsc.li/molecular-engineering

Two years on from our inaugural MSDE emerging investigators issue, we are proud to introduce the second iteration of this initiative. As before, our Editorial and Advisory Boards selected for invitation leading early-career researchers who are applying molecular engineering approaches, both to tackle fundamental scientific questions and to address the development of new technologies and materials.

The topics and approaches covered in the issue display all the diversity and variety we have come to expect from MSDE papers.

Many of the contributions address specific technologies, ranging from $\mathrm{Li}$ ion batteries (DOI: 10.1039/ C 9ME00104B, DOI: $10.1039 /$ C9ME00067D, and DOI: 10.1039/ C9ME00084D), to therapeutics (DOI: 10.1039/C9ME00088G, DOI: 10.1039/ C9ME00092E, and 10.1039/ C9ME00118B), sensing applications (DOI: 10.1039/C9ME00142E, DOI: 10.1039/C9ME00147F, and DOI: 10.1039/C9ME00135B), and porous materials for capture and separation (DOI: 10.1039/C9ME00102F, DOI:
10.1039/C9ME00132H, and DOI: 10.1039/C9ME00072K). A number of papers also investigate processes critical to key manufacturing technologies, such as vapour deposition (DOI: 10.1039/ C9ME00087A and DOI: 10.1039/ C9ME00100J) and crystallisation (DOI: 10.1039/C9ME00042A, DOI: 10.1039/ C9ME00063A and DOI: 10.1039/ C9ME00103D).

Most contributions are experimental studies, though computational approaches are also well represented, such as molecular simulations of liquid crystal sensors (DOI: 10.1039/C9ME00126C); mathematical optimization and DFT calculations of transition metal nanoclusters (DOI: 10.1039/C9ME00108E); computational screening of MOFs for $\mathrm{CO}_{2}$ capture (DOI: 10.1039/ C9ME00102F); and a machine learning approach applied to rational drug design (DOI: 10.1039/C9ME00109C).

We'd like to take this opportunity to thank all of the authors and referees who have supported the journal thus far. We strongly advise readers to survey all the contributions contained in this issue!

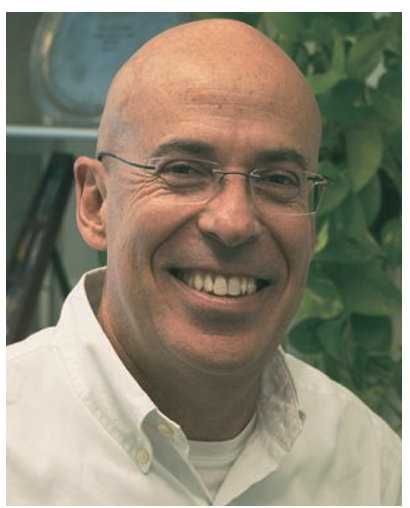

Juan de Pablo Editorial Board Chair

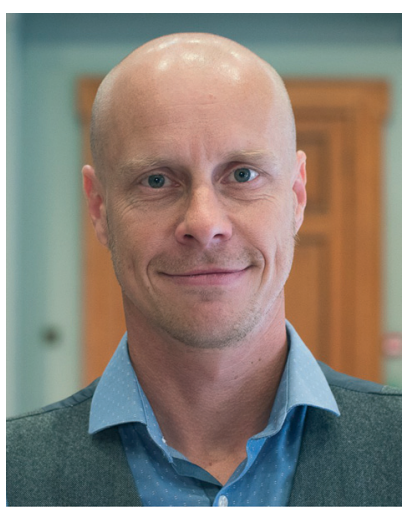

Neil Hammond Executive Editor 